You will see also specimens of myelitis, following fracture of some of the bodies of the vertebræ and consequent hæmorrhage, from the case brought before you by Dr. Beddoe on a recent occasion. The section shews great increase of the connective tissue ; no amyloid bodies; special diminution of the elements of the grey matter, the multipolar cells being few in number; and a great deal of granular matter in the place of the grey substance.

Lastly, there is a specimen for the middle of the cervical bulb of the cord, shewing a different form of sclerosis, in a case of general paralysis of the insane. The disease here shews itself in the white matter, and to a less degree in the grey, in the form of small masses of semitransparent material, with more or less irregular outline. The posterior columns are chiefly affected.

In a meeting composed of busy practical men, it would be scarcely seemly to leave untouched the question of treatment, and it is as bearing upon treatment that a knowledge of the pathological anatomy is so important. For what, after all, is usually the main lesion in myelitis, except in the most rapidly fatal cases? It is increase of the connective tissue, and disintegration of the nervous elements consequent on this increase. Now this increase of connective tissue is a proof that we have to deal with a slow inflammatory process. Softening may take place rapidly; induration is invariably gradual. This being granted, and it being now known that we have to deal with a similar lesion, affecting various portions of the cord in paraplegia from myelitis, in many cases of infantile paralysis, in locomotor ataxy, and in some cases, at least, of progressive muscular atrophy, we have before us two principles of treatment, one to support the patient by food, rest, and warnith, and the other to improve the tone of the altered vessels. In acute cases, the use of leeches, blisters, etc., is contra-indicated, partly by the fear of bed-sores, partly by the tendency to depression induced by lesion of so important an organ as the spinal cord. A better effect is obtained by the use of the spinal ice-bag. My own experience points to the advisability of using it alternate hours, watching the pulse carefully meanwhile. It relieves acute symptoms, depresses the temperature, and enhances the comfort of the patient. The drugs most useful in the treatment of these cases are strychnine and ergot; strychnine in the more chronic cases, ergot in the more acute. In infantile paralysis, strychnine will help towards a perfect cure; in progressive muscular atrophy, in locomotor ataxy, and in chronic myelitis, it puts off the evil day, and improves the condition of the patient amazingly; and although acute myelitis is a fatal condition, and may end in death, even in eighteen or twenty hours, yet, in many cases, the combined use of the icebag and of ergot will prolong life, and in some few instances may allow acute myelitis to become chronic. I am far from mentioning these remedies as alone useful, but one cannot help speaking well of what has been found advantageous in one's own practice.

\section{BROMIDE OF POTASSIUM AS A FEBRIFUGE.}

\section{By CHARLES MACLEAN, M.B., Applecross.}

THE following particulars of a case, taken from my notes, illustrate the value of bromide of potassium in fevers. It came under my care on January $\mathrm{Ioth}$; and, as it was a convenient one for observation, I resolved to give a fair trial to the medicine. I had a confidence in it, grounded on some former experience of its efficacy ; but the result, I am bound to say, exceeded my expectation. The following are the details.

January Ioth. B., a well-nourished woman, aged about 40 , was taken ill four days ago, with a well-marked attack of enteric fever. Pulse, I 40 ; temperature, 1052 deg. Fahr. The respiration was hurried; some sibilant rales were heard over both lungs. The expression of countenance was anxious. The tongue was red at the edges, with a whitish fur down the middle. The bowels were relaxed; the evacuations somewhat bloody. There was tenderness on pressure in the right iliac region. I gave a dose of chalk mixture, with ten minims of tincture of opium, to be followed by twenty grains of bromide of potassium
three times a day.

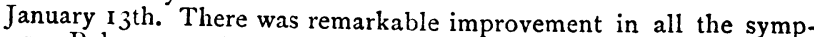
toms. Pulse, 100 ; temperature, IOI deg. F. The characteristic peasoup stools were present, without any blood. There was occasional cough, but hardly as troublesome as on this last day. The respiration was little, if anything, above the normal in frequency. Some pain was still occasionally felt in the right iliac region. The bromide was continued as before.

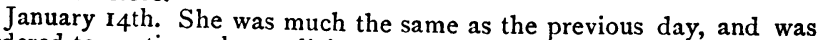
ordered to continue the medicine, with milk and farinaceous diet.

January I5th. She was improving. Pulse, 94 ; temperature, 99.5 deg. The evacuations were less frequent, and of the same character.
The tongue was clean and moist. The countenance was placid. She was ordered to continue as before.

January $I$ th. The medicine was omitted.

January igth. Pulse, I 6 ; temperature, Ioo deg. The tongue had become, as at first, furred in the middle, and was protruded tremulously. The face was flushed and anxious. Respirations 45 in the minute. Sibilus was heard extensively over the chest, but no small crepitation was audible, on the most careful examination. Thirst was complained of. The bromide was recommenced at once; and diluents were given ad libitum.

January 22nd. Pulse, 90 ; temperature, $98 \mathrm{deg}$. The countenance had a cheerful expression. The tongue was uniformly clean. The bowels were well. The cough was sometimes troublesome, but the respirations were 22 in the minute.

January 23 rd. The dose of bromide was reduced to twelve grains.

On the 29th, convalescence was quite established; and on the 3 Ist she was up most of the day and fast gaining strength.

In the intervals between the Ioth and I 3 th, and 19 th and 21 st, I was unavoidably absent; but, from what I could gather, an improvement took place on both occasions in thirty or thirty-six hours after the bromide was commenced. I reduced the dose on the $23 \mathrm{rd}$, because the temperature remained at $98 \mathrm{deg}$. F., a little lower than I thought necessary, and I feared a reactionary movement might take place if she were kept too deeply under its influence.

If the facts of this case prove nothing as to the efficacy of the bromide, there must have been one or two remarkable coincidences in the case. I am, however, of opinion, from what I have before seen of it, that there was more than mere coincidence in the matter.

A word as to the physiological action. If, as I believe, bromide of potassium acts by constricting or giving tone to the minute vessels directly, it is calculated to strike at the very root of the disease in fever; for it will then take the place of the paralysed vaso-motor system of nerves, and thereby keep in abeyance that inevitable tendency to congestion that follows the premonitory stage of the disease-the stage characterised by excitement or rigor.

If this view be correct, it is, I think, obvious that the use of the bromide in the treatment of pyrexia is much more in accordance with physiological principles than the direct application of cold ; for, however useful the treatment by cold water may be, one thing we must remember is, that we are not treating heat, for temperature is a mere symptom of disease ; an useful index, no doubt, of the degree of mis. chief and oxidation of the elements going on in the system.

\section{LEPROSY OF THE JEWS.}

\section{By BENJAMIN BLOWER, M.R.C.S.Eng., Liverpool.}

I HAVE been much interested with the lectures and letters on leprosy, which have lately appeared in the JOURNAL, but I do not think the leprosy of the Jews is a subject by any means exhausted; and, therefore, beg permission to add a few lines. In studying the Scriptures, we should endeavour to divest our minds of everything apart from the object of revelation. However interesting in a sanitary point of view the laws given to Israel may be, we must remember that "salus populi lex suprema" is not the object of the book, but the affairs of the soul.

Turning to Leviticus, chapter xiii, we find the priest not endowed with power to heal, for this the law could not do; but with directions to distinguish two kinds of leprosy from other allied diseases which, apparently infectious, were not unclean. The leper white all over, was not unclean, or kept apart; Gehazi talks with the king in the gate of justice (Second Kings, chap. viii, verse 4). Even among the Syrians Naaman was a great man with his master (Second Kings, chap. v, verse I). But the leper with raw flesh is unclean; his disease is of all others the most loathsome and disgusting, incurable by human efforts, and transmissible to his offspring. He must dwell outside the camp we are not told it was on account of contagion. Other infectious diseases are not so separated; for example, "The Lord shall smite thee with the itch, whereof thou canst not be healed" (Deut. ch. xxviii, v. 27 ); " and the plague, spread not in the skin, the priest shall pronounce him clean, it is but a scab, he shall wash his clothes and be clean" (Lev. ch. xiii, v. 6); "a sore botch that cannot be healed" (Deut. ch. xxviii, v. 35). Unclean evidently means unlawful for use by a typical people. The altar and the priest had to be cleansed, and "almost all things were purged with blood" (Heb. ch. ix, v. 22). The spiritual significance of this separation is not for discussion in a journal devoted to medicine; but from what has been said I take it for granted it was not on the score of health, but "that they defile not the camps, in the midst of which I (the Lord) dwell" (Num. ch. v, v. 
3). Even when healed, the leper was put through a ceremony called cleansing before he could take his place in the congregation. It is remarkable that in the Old Testament there is only one instance (Miriam's) of an Israelite's recovery. Our Lord complains of this want of faith in the healing power given to the prophets, when he says, "and many lepers were in Israel in the time of Eliseus the prophet; and none of them were cleansed saving Naaman the Syrian" (Luke ch. iv, v. 27).

I am not anxious to make the Bible agree with the shifing sands of science; but when great pains have been taken to investigate a subject, and the results appear contradictory to the popular notions of the scriptires, it is well we should read the text again. Doing so, I now think that no one can dogmatically say that the sacred writings are opposed to the non-contagious opinions of modern investigators.

\section{CLINICAL MEMORANDA.}

ON COMMINUTED FRACTURE OF THE CLAVICLE. THE interesting case of comminuted fracture of the clavicle, which appeared in the JouRnAL of June 7 th, and the valuable com mentary on it by Mr. Erichsen, entitle it to serious attention. As it is an accident that may occur at any time or anywhere, it behoves the surgeon, in face of the fatal issue of this case, to inquire whether it may not furnish suggestions for guidance in the management of casualties like it, with a view to preventing the secondary effects on the arm arising from mechanical pressure on the blood-vessels and absorbents, and on the axillary plexus by portions of the fractured bone. Would it be a hopeful or justifiable procedure to divide the integuments, and, by removing loose portions of bone, relieve from pressure the important parts beneath? Encouragement is given to such a step by the very few and exceptional cases in which laceration of the subclavian artery or vein has occurred, $*$ by the tolerant power in the clavicle of bearing severe surgical operations for its removal, and by the means we possess of promoting adhesion of the wound by first intention.

THOMAS T, GRIFFITH

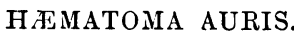

I AN able to supplement the very interesting paper of Dr. Yeates, on Hæmatoma Auris, in your last week's issue, by the statement that I have also seen a case of recovery in which this complica. tion existed. A young man was attacked with acute mania, in October 1861 , and came under my care in this asylum, within a week after the attack commenced. For twelve months no improvement took place, but the patient seemed to be rapidly proceeding in the direction of dementia, and for some time there had been hæmatoma of both ears, with the effusion, absorption, and subsequent disfigurement, which mark that peculiarity. A change then suddenly occurred; the excite. ment passed away, the habits improved, the general mental condition became entirely satisfactory, and the patient was discharged, recovered, sixteen months from the date of his admission, and up to this time, a period of more than ten years, he has remained perfectly well, and been practising his profession.

Unless for the publication of Dr. Yeats' paper, it would not hare occurred to me to place this case on record; and it is therefore not im. probable that the superintendents of other asylums have met with similar instances, a report of which would materially affect the pro. gnosis to be given in cases of insanity where this complication exists. Its striking diminution of late years would seem to point to a very definite conclusion as to its general causation. I have certainly found, in my own experience, that its appearance has been materially influ. enced by the expressed assumption that it is invariably associated with violence, somehow exercised, and for which some one shall be made responsible.

The Asylum, Bootham, York, June 21st, 1873

\section{THERAPEUTIC MEMORANDA.}

\section{GLYCERINE AS AN APERIENT.}

IN the last number of the Journal, Dr. Snow proposes the combination of glycerine with the perchloride of iron, to cover the "astringent metallic taste" of the latter. I have for a long time

* S. Cooper, in his Surgical Dictionary, states that, up to 1838 , "I am not aware of any case in which the subclavian vessels have been wounded by the spicula of a broken clavicle"; and this assertion is very much confirmed by Mr. Erichsen.

+ In the Medico-Chirurgical Transactions, vol. xxi, page 125, there are five cases of removal of the clavicle, collected by Mr. Travers, including one of his own, all of which ended successfully. adopted this in my own practice, not with the view, bowerer, of merely covering the astringent taste, but to counteract its astringent effect on the bowels, where this is not required. Indeed, I think glycerine might with advantage be substituted for syrup in every case where the latter is prescribed as a vehicle for other medicines, such as the various preparations of iron, cinchona, rhatany, etc., which have a tendency to constipate; besides which, glycerine keeps better than syrup, its solvent powers are greater, and it possesses all the advantages of syrup without any of its inconveriences.

ALEx. Boggs, M.D., late of H.M. Indian Army.

13, Boulevard de Courcelles, Paris, lst July, 18 i3.

\section{AN ESTHETICS.}

XIv.

THE number of communications which we have received on this important subject exceeds the space at our disposal for their publication. We have had the great satisfaction of arousing the most wide-spread renewed interest in the subject, and fully awakening medical men to a sense of the dangers of chloroform, and to a perception of the duty of publishing the record of all serious or fatal accidents from it as from other anæsthetics. The multiplied evidence adduced in our pages of the apparently greater relative safety of ether has secured for that anæsthetic, of which the use had almost died out, a fresh trial in many of our largest hospitals, and thus far with satisfactory results. The question, however, still remains open, and its opportuneness is not diminished. In Ireland, thanks very much to the exeritions of Lr. Morgan, ether is being largely employed, and the special report of the committee of the Surgical Society which we have noticed, although in. complete, is much to the point. We have seen with satisfaction that the medical press generally has followed our example during the last few months in bringing the subject into notice, and we contribute below some further materials for the solution of the problem.

[For a very complete summary of what has already appeared in this Journal, we may refer to a series of abstracts by Dr. John Murray in the London Mcdical Record, of April 2:3rd, 30ih, Mlay 7 th, 1tth, 21st, 28 th, and June 4 th.]

XV.-ON the conparative advantages of ether aNd Chloroform AS ANESTHETICS.

Mr. Arthur Fergusson McGimi, in a paper read befure the Leeds and West Riding Medico-Chirurgical Society, says :-

The subject of anæsthesia is so important, and such various opinions are held as to the merits of the different anæsthetics, that I feel that it is unnecessary for me to apologise for bringing the subject before you this evening. At the present time, in general surgery, the choice seems to lie between two drugs, chloroform and ether. Bichloride of methylene and the laughing.gas are both useful; the latter in the shortest operations, as, for example, in the extraction of a tooth; the former in those slightly more prolonged, e.g., in iridectomy and the like. In longer operations they are seldom adopted.

Which, then, shall we use, ether or chloroform? The question is a difficult one to answer; for both have their advantages, both their disadvantages. Before doing so, $I$ will in a few words describe the methods which I consider best for administering both drugs. Chloroform is best given on one thickness of lint by means of a drop.bottle any bottle will do, a cork with a slit in the side enabling you to drop as well as the most complicated stopner. After the first feeling of suffocation is past, give as much as you can; put the lint close over the patient's mouth and pour on plenty of chloroform. Theoretical writers say, never give air containing more than 4 per cent. of chloroform vapour; I do not know how many per cent. I give, but I give as many as $I$ can.

Many inhalers have been invented to administer ether with; nothing, as far as I know, answers better than a large sponge covered with waterproof. Heat this in warm water, wring it as dry as possible, pour into it an ounce or so of ether, and hold it tightly over the patient's face; and in one or two minutes he is insensible.

The chief advantage attending the use of ether is that it is a safer anæsthetic than chloroform. Statistics tend to show that there is only 1 death in 24,000 administrations against 1 in 3,000 of chloroform. These statistics have a certain amount of value, and anyone who has used both drugs many times can easily believe they are true. The chief danger from chloroform arises from cardiac svncope; the heart falls, the pulse stops, and colour leaves the cheeks and lips. This is a condition of imminent danger, and fortunately seldom occurs if the administrator be attending to his patient. He, however, is prone to 